\title{
2-Aminoadipic acid protects against obesity and diabetes
}

\author{
Wang-Yang Xu1,2,*, Yan Shen 1,*, Houbao Zhu1,*, Junhui Gao², Chen Zhang², Lingyun Tang1, Shun-Yuan Lu', \\ Chun-Ling Shen', Hong-Xin Zhang1, Ziwei Li², Peng Meng², Ying-Han Wan³, Jian Fei³ and Zhu-Gang Wang1,3,4
}

1State Key Laboratory of Medical Genomics, Research Center for Experimental Medicine of Rui-Jin Hospital, Shanghai Jiao Tong University School of Medicine, Shanghai, China

2Biotecan Medical Diagnostics Co., Ltd, Zhangjiang Center for Translational Medicine, Shanghai, China

${ }^{3}$ Shanghai Research Center for Model Organisms, Shanghai, China

4Model Organism Division, E-Institutes of Shanghai Universities, Shanghai, China

Correspondence should be addressed to Z-G Wang: zhugangw@shsmu.edu.cn

*(W-Y Xu, Y Shen and $\mathrm{H}$ Zhu contributed equally to this work)

\begin{abstract}
Obesity and type 2 diabetes (T2D) are both complicated endocrine disorders resulting from an interaction between multiple predisposing genes and environmental triggers, while diet and exercise have key influence on metabolic disorders. Previous reports demonstrated that 2-aminoadipic acid (2-AAA), an intermediate metabolite of lysine metabolism, could modulate insulin secretion and predict T2D, suggesting the role of 2-AAA in glycolipid metabolism. Here, we showed that treatment of diet-induced obesity (DIO) mice with 2-AAA significantly reduced body weight, decreased fat accumulation and lowered fasting glucose. Furthermore, Dhtkd1-/- mice, in which the substrate of DHTKD1 2-AAA increased to a significant high level, were resistant to DIO and obesity-related insulin resistance. Further study showed that 2-AAA induced higher energy expenditure due to increased adipocyte thermogenesis via upregulating PGC1 $\alpha$ and UCP1 mediated by $\beta 3 A R$ activation, and stimulated lipolysis depending on enhanced expression of hormone-sensitive lipase (HSL) through activating $\beta 3 A R$ signaling. Moreover, 2-AAA could alleviate the diabetic symptoms of $d b / d b$ mice. Our data showed that 2-AAA played an important role in regulating glycolipid metabolism independent of diet and exercise, implying that improving the level of 2-AAA in vivo could be developed as a strategy in the treatment of obesity or diabetes.
\end{abstract}

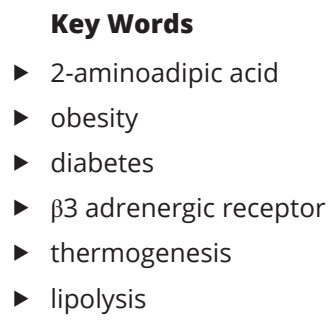

\section{Introduction}

Obesity is a severe public health issue worldwide featured by irregular glucose, lipid and hormone metabolism and imbalanced energy expenditure. Obesity is usually present combined with detrimental comorbidities including T2D, insulin resistance, nonalcoholic fatty liver disease (NAFLD), inflammation, and even cancer risk (Flegal et al. 2013, Gonzalez-Muniesa et al. 2017),

threatening human lives and influencing the quality of life (Calle et al. 2003, Jensen et al. 2014). T2D is a complicated disorder characterized by hyperglycemia in the setting of insulin resistance (Ashcroft \& Rorsman 2012). Causes of T2D are not separated from chronic persistent glucotoxicity (hyperglycemia) and lipotoxicity (elevated lipid levels) (Alejandro et al. 2015). 
Reducing obesity and associated T2D through diet, exercise and pharmaceuticals brings about health benefits (Colberg \& Sigal 2011, Fildes et al. 2015).

In humans, adipose tissues are divided into white adipose tissue (WAT) and brown adipose tissue (BAT) according to their functions (Klaus 1997). The main function of WAT is storing energy as a triglyceride when the energy intake is excessive, and meanwhile, hydrolyzing triglyceride and releasing free fatty acid when the energy intake is inadequate. The main function of BAT is thermogenesis, that is, providing heat for life activities (Kajimura et al. 2010). BAT contains a large number of mitochondria and a large amount of mitochondrial uncoupling protein 1 (UCP1) is expressed in the inner membrane of mitochondria, participating in the transmission of electron transfer chains to producing heat through cellular respiration and mediating energy expenditure (Argyropoulos \& Harper 2002, Ricquier 2005). Previous evidence demonstrated that obesityresistant mice had a higher expression of UCP1 in WAT relative to obese controls (Xue et al. 2007). It has also been known that the activation of UCP1 in beige adipocyte could increase energy expenditure and resist DIO and insulin insensitivity (Guerra et al. 1998). The functional mechanism of UCP1-mediated thermogenesis was boosted in recent years by the discovery of UCP1expressed adipocyte, which could be induced in some WATs (beige fat) of mice to induce fat burning in response to stimuli (Wu et al. 2012, Shabalina et al. 2013). Chronic stimulation of $\beta 3$ adrenergic receptor ( $\beta 3 \mathrm{AR}$ ) could convert WAT into a tissue resembling BAT, which was called 'browning' of white fat (Seale et al. 2011, Lee et al. 2012, 2014). Despite thermogenesis, $\beta 3 \mathrm{AR}$ expression and $\beta 3$ AR-mediated lipolysis have been documented in human visceral adipocytes (Lonnqvist et al. 1993, 1995, De Matteis et al. 2002, Lafontan \& Berlan 2003, YehudaShnaidman et al. 2010). In 'browning' adipocytes, the free fatty acids produced by $\beta 3$ AR-mediated lipolysis are used up for thermogenesis via UCP1 (Ricquier et al. 1986, Yehuda-Shnaidman et al. 2010). The activation of $\beta 3 \mathrm{AR}$ pathway in the white adipocytes makes $\beta 3 \mathrm{AR}-\mathrm{based}$ lipolysis and thermogenesis become a new therapeutic strategy against obesity and diabetes.

2-AAA is a potential regulator of glucose homeostasis, which is higher in T2D patients and considered to be a biomarker for T2D mellitus (Wang et al. 2013). But, dramatically, 2-AAA is able to promote insulin secretion and decrease blood glucose in mice (Wang et al. 2013, $\mathrm{Xu}$ et al. 2018). Dehydrogenase E1 and transketolase domain-containing 1 (DHTKD1) protein is a component of $\alpha$-ketoadipic acid dehydrogenase complex, which is involved in the metabolism of lysine, hydroxylysine and tryptophan (Hagen et al. 2015). DHTKD1 deficiency or mutation affects mitochondrial oxidative phosphorylation and energy metabolism (Xu et al. 2012, 2013). Loss of function of DHTKD1 causes accumulation of intermediate metabolite 2-AAA in humans and mice (Danhauser et al. 2012, Xu et al. 2018).

In the current study, we evaluated the effect of 2-AAA on lipid metabolism and found that it activated $\beta 3 \mathrm{AR}$ signaling to protect against obesity and diabetes. Furthermore, 2-AAA obviously ameliorated metabolic status of $d b / d b$ mice. This provides a novel insight on lipid metabolism and reveals the potential pharmaceutical value of 2-AAA.

\section{Materials and methods}

\section{Mice}

The whole-body knockout Dhtkd1-/- mice had been reported previously ( $\mathrm{Xu}$ et al. 2018) and the $d b / d b$ mice were purchased from Nanjing Biomedical Research Institute of Nanjing University. All mice were maintained in a standard specific-pathogen-free condition and free access to diet and water unless otherwise specified. Only male mice were chosen to participate in this research. High-fat diet (HFD) (diet with $60 \mathrm{kcal} \%$ fat, Research Diets) and 2-AAA (Sangon Biotech) drinking water were executed since the mice were 1 month old. All procedures were approved by the Animal Ethics Committee of Rui-Jin Hospital.

\section{Body composition and indirect calorimetry}

Body composition (fat and lean mass) was assessed via quantitative nuclear magnetic resonance relaxometry using an EchoMRI whole-body composition analyzer. Mice were housed individually in LabMaster system (TSE Systems), and after 2 days for the adaptation, indirect calorimetry was measured for 5 consecutive days.

\section{Histopathological analysis}

Mouse tissues were isolated and fixed in 10\% formalin and sectioned. The staining procedures were performed routinely, including hematoxylin and eosin (H\&E) staining, oil-red staining and PAS staining. Besides, mouse liver and BAT were dissected and fixed in 
$2.5 \%$ glutaraldehyde and semithin sections were stained with toluidine blue. Then, the transmission electron microscopy (TEM) was carried out using Philips CM120 instrument at Shanghai Jiao Tong University School of Medicine.

\section{Serum biochemical analysis}

The blood samples of mouse taken from retrobulbar vein were centrifuged and the sera were analyzed with an automatic biochemical analyzer. Blood leptin and insulin contents were determined using ELISA method with mouse leptin ELISA kit (Crystal Chem) and insulin ELISA kit (Mercodia), respectively.

\section{GTT and ITT}

Mice fasted overnight for $16 \mathrm{~h}$ were injected intraperitoneally with $2 \mathrm{~g}$ of glucose per kilogram body weight. Blood samples accessed from the tail vein were collected at the specific time points after injection, and glucose levels were measured using a glucometer (Sinocare). On the other hand, mice fasted for $6 \mathrm{~h}$ were intraperitoneally injected with $0.75 \mathrm{U} / \mathrm{kg}$ human insulin (Humulin; Lilly). Tail blood samples were collected and measured with a glucometer (Sinocare) at the specific time points after injection.

\section{Cell culture and treatment}

The 3T3-L1 cells (ATCC ${ }^{\circledR}$ CL173 ${ }^{\mathrm{TM}}$ ) were purchased from American Type Culture Collection and were cultured in Dulbecco's modified Eagle's medium (DMEM) complete medium containing $10 \%$ heat-inactivated bovine calf serum, $100 \mu \mathrm{g} / \mathrm{mL}$ streptomycin and 100 units $/ \mathrm{mL}$ penicillin at $37^{\circ} \mathrm{C}$ in a $5 \%$ humidified $\mathrm{CO}_{2}$ atmosphere. For the experimental group, $20 \mu \mathrm{M}$ 2-AAA (Sigma-Aldrich) was added to the medium.

\section{Quantitative reverse transcription-PCR (qRT-PCR)}

Total RNAs were extracted from mouse adipose tissues or cultured cells using TriPure reagent (Roche) and were reverse transcribed into cDNAs using a reverse transcriptase reagent kit with genomic DNA eraser (TaKaRa) according to the manufacturers' instructions. Quantitation was carried out using a SYBR green PCR kit (TaKaRa) in Mastercycler ep realplex instrument (Eppendorf). Relative transcript quantities were calculated using the $\Delta \Delta C_{T}$ (threshold cycle) method with $\beta$-actin as an endogenous reference gene. Each sample was analyzed in triplicate and primers listed in Supplementary Table 1 (see section on supplementary data given at the end of this article) were accessed from the PrimerBank database (Spandidos et al. 2010).

\section{Western blot analysis}

Adipose tissues or cells were lysed using lysis buffer, which contained 1\% Nonidet P-40, 0.5\% sodium deoxycholate and $0.1 \%$ SDS in PBS supplemented freshly with protease and phosphatase inhibitor cocktails (Roche). Proteins were separated by SDS-PAGE, transferred to nitrocellulose membranes and probed with specific primary antibodies as follows, anti-UCP1 (Santa Cruz), anti-PGC1 $\alpha$ (Santa Cruz), anti-PPAR $\gamma$ (Santa Cruz), anti-ATGL (Cell Signaling Technology), anti-perilipin A (Sigma-Aldrich), anti-HSL (Cell Signaling Technology), anti-pHSL (Cell Signaling Technology), anti- $\beta 3$ AR (Abcam), anti-PKA (Cell Signaling Technology), anti-pPKA (Cell Signaling Technology), anti-p38 (Cell Signaling Technology), anti-pp38 (Cell Signaling Technology), anti-Actin (Cell Signaling Technology), anti-Tubulin (Sigma-Aldrich), and antiGAPDH (Sangon Biotech).

\section{Molecular simulation}

The structural data of 2-AAA were from PubChem and the structure of $\beta 3 \mathrm{AR}$ were obtained through homologous modeling referring to the structure of $\beta 2 \mathrm{AR}$ (PDB code, 5X7D) in Protein Data Bank using SWISS-MODEL. Then, the binding pocket of ARs was calculated and identified according to the location of the natural small molecules and the shape and volume of 2-AAA. Finally, molecular docking of ARs and 2-AAA was carried out by ArgusLab software.

\section{Statistical analysis}

All data were presented as means \pm S.D. and a two-tailed Student's $t$ test was used to compare the differences between two groups. A $P$ value of less than 0.05 was used to define statistical significance $\left({ }^{*} P<0.05,{ }^{* *} P<0.01\right.$, and $\left.{ }^{* * *} P<0.001\right)$. 


\section{Results}

\section{2-AAA protected against DIO via increasing energy expenditure in mice}

To elucidate the role of 2-AAA on metabolism, we conducted daily treatment of C57 mice with $2.5 \mathrm{~g} / \mathrm{L}$ of 2 -AAA on either a standard chow diet (SCD) or HFD for 24 weeks. Interestingly, the body weight of 2-AAA-treated mice was significantly lighter than that of controls, especially when they were fed with HFD (Fig. 1A). From the photographs of mice, we found that 2-AAA-treated mice were slenderer than controls whether they were fed with SCD or HFD (Fig. 1B). Besides, 2-AAA-treated mice accumulated less fat in the abdomen compared to controls (Fig. 1B). Body composition analyses showed that the percentage of fat mass and lean mass both increased pronouncedly under HFD (Fig. 1C). However, 2-AAA-fed mice displayed a significant reduction in lean body mass without an alteration in fat mass on SCD. On the HFD, a significant decrease in body weight in the 2-AAA-treated mice was mainly due to a marked reduction in the percentage of fat body mass (Fig. 1C). Both the sizes of BAT and epididymal (visceral) and subcutaneous WAT of 2-AAA-treated mice on either SCD or HFD were smaller compared to those of controls (Fig. 1D). Next, organ weight showed that the weights of adipose tissues of 2-AAA-treated mice were less than those of controls fed with HFD, but with no alteration in liver and kidney (Fig. 1E). Histological analysis showed the adipocyte sizes of 2-AAA-treated mice were smaller than those of controls when they were fed with HFD (Fig. 1F). Chronic exposure to HFD could cause fatty liver containing large lipid-containing vacuoles. However, less lipid droplets accumulated in the liver of 2-AAA-treated mice were observed (Fig. 1F). The serum leptin was significantly decreased in 2-AAA-treated mice when they were fed with HFD (Fig. 1G). Plasma lipidprofile testing showed that the total cholesterol (TC), triglyceride (TG) and low-density lipoprotein cholesterol (LDL-C) levels of 2-AAA-treated mice were significantly lower than those of controls, while the other blood biochemical indexes were comparable (Supplementary Fig. 1). This is a rather interesting result that 2-AAA could protect mice against DIO. The lower body weight of 2-AAA-treated mice was closely related to a large reduction in fat mass. Food intake was of no significant difference between the groups (Supplementary Fig. 2A), suggesting that the obesity-resistant effect is primarily
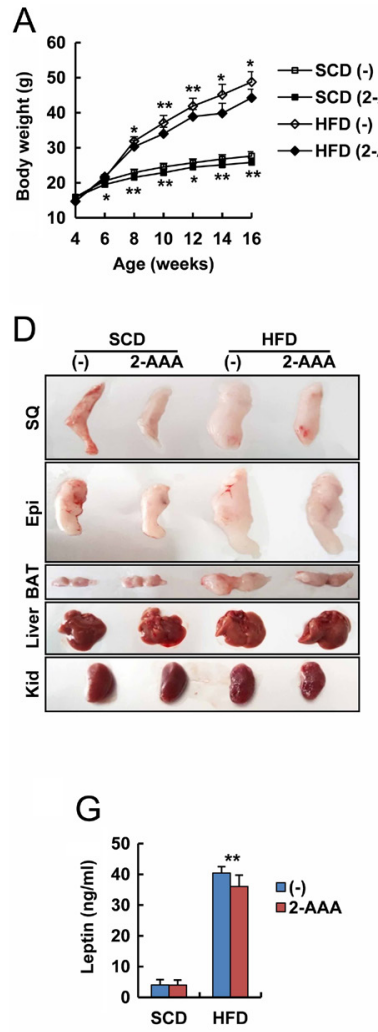
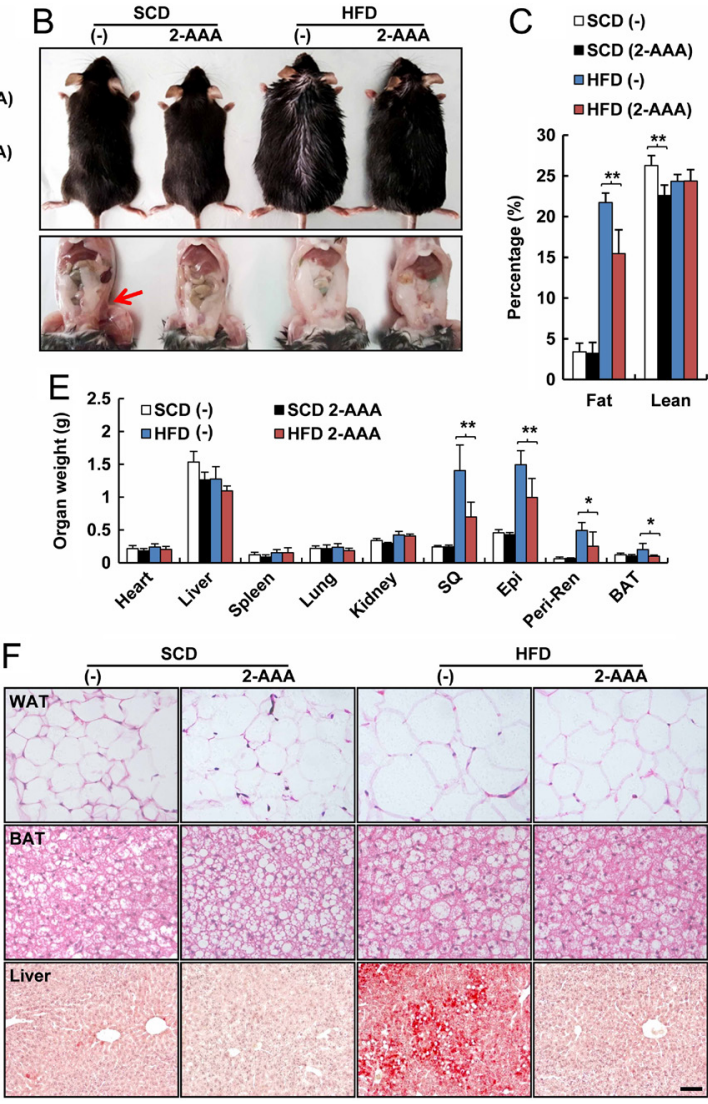

Figure 1

2-AAA intake protects mice against obesity. (A) Body weights of mice ( $n=12$ mice/group). (B) Photographs of mouse morphology and anatomical abdomen. (C) MRI analysis shows the contents of fat mass and lean mass ( $n=5$ mice/ group). (D) Photographs of isolated adipose tissues, liver and kidney. (E) Isolated organ weights of mice ( $n=5$ mice/group). (F) HE staining of adipose tissues and oil-red staining of liver. Scale bar, $100 \mu \mathrm{m}$. (G) Serum leptin levels of mice ( $n=8$ mice/group). A full colour version of this figure is available at https://doi.org/10.1530/ JOE-19-0157. 
associated with altered metabolism, such as enhanced energy expenditure and heat production. Indirect calorimetry studies of 2-AAA-treated mice revealed an increase in the heat production during both day and night (Supplementary Fig. 2B), while the locomotor activity of 2-AAA-treated mice in the metabolic cage was comparable with controls (Supplementary Fig. 2C). The respiratory exchange ratio (RER) was elevated in 2-AAA-treated mice (Supplementary Fig. 2B), suggesting a markedly increased use of glucose as an energy source. Additionally, the increases in $\mathrm{O}_{2}$ consumption and $\mathrm{CO}_{2}$ exhalation were detected in 2-AAA-treated mice compared with those of controls (Supplementary Fig. 2B). These reveal that the emaciation of 2-AAA-treated mice is mainly due to their high energy expenditure.

\section{Dhtkd1-/- mice were resistant to DIO due to enhanced energy expenditure}

Now that 2-AAA could protect mice from predisposing to obesity, we consider how to increase the level of 2-AAA in vivo. Previously, we proved that Dhtkd1-knockout (Dhtkd1-/-) mice whose urine 2-AAA levels were increased by about 120 times due to Dhtkd1 deficiency (Xu et al. 2018). We speculate that the deletion of Dhtkd1 could cause the accumulation of its substrate, 2-AAA. Otherwise, we found the expression of DHTKD1 protein was regulated by diet and cold stress. It increased when the mice were fasted and recovered after refed. And it decreased when the mice were exposed into cold environment (Supplementary Fig. 3). All above implied the role of DHTKD1 in energy metabolism. Besides, in our daily observations, we found Dhtkd1 $1^{--}$mice were slightly thinner and smaller than wt mice, which was much more obvious when they were fed with HFD (Supplementary Fig. 4A). Dhtkd1 $1^{-/-}$mice appeared normal at birth, but showed decreased body weight compared with agematched littermates after weaning. These differences were more obvious when given an HFD diet, because wt mice became obese rapidly. In contrast, Dhtkd1-/- mice maintained approximately the same body weight on HFD as on SCD (Fig. 2A). The photographs of anatomical abdomen showed that Dhtkd1-/- mice accumulated less fat than wt mice whether they were fed with SCD or HFD (Fig. 2B). Body composition analyses showed that HFD-fed Dhtkd1 1-/- mice had marked less fat as a percentage of total body weight compared with wt mice (Fig. 2C), resembling the effects of 2-AAA treatment. The percentage of lean mass was comparable between Dhtkd1-/- mice and wt mice (Fig. 2C). Further anatomy showed that the weights
A
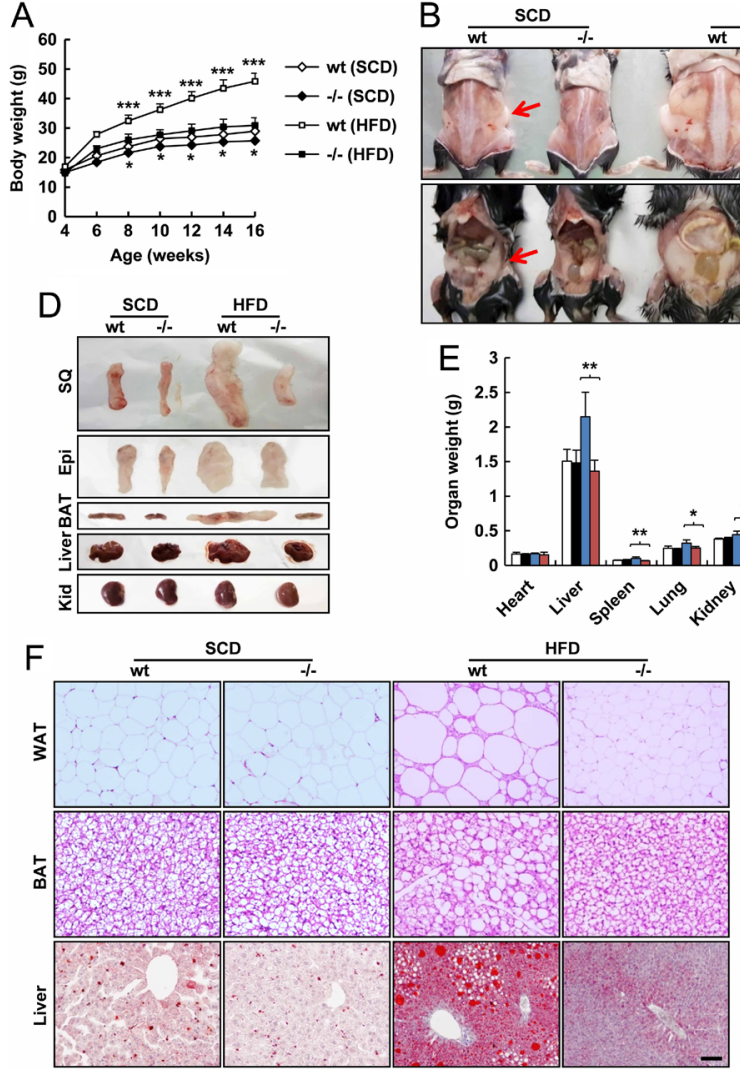
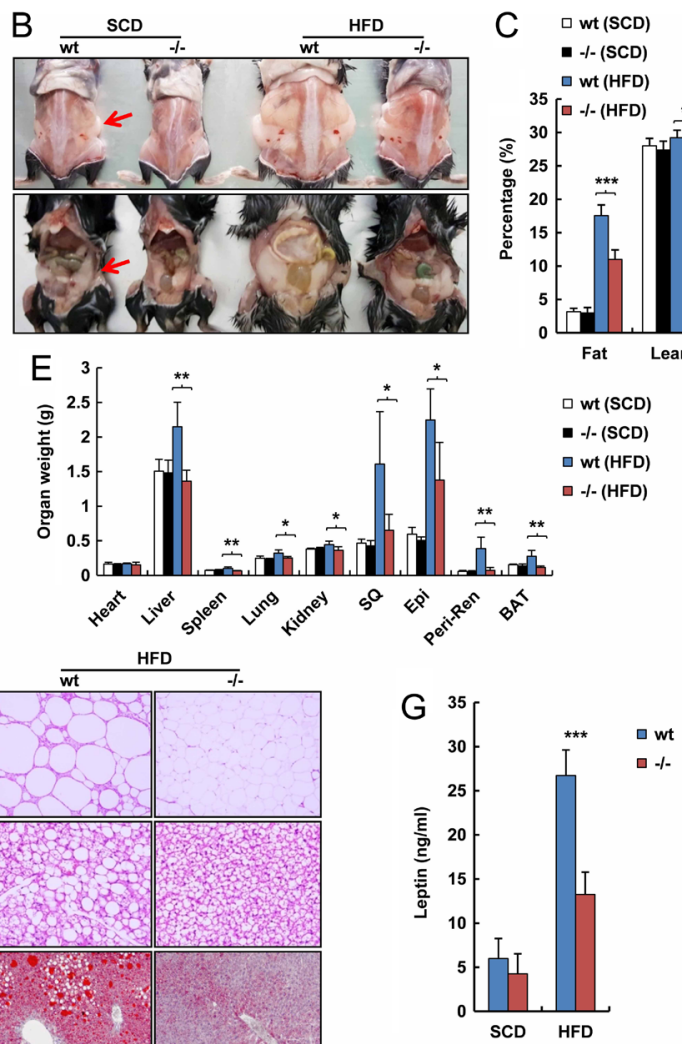

Figure 2

Dhtkd1 deficiency protects mice against obesity. (A) Body weights of mice ( $n=10$ mice/group). (B) Photographs of anatomical abdomen of mice. (C) MRI analysis of the contents of fat mass and lean mass ( $n=5$ mice/group). (D) Photographs of isolated adipose tissues, liver and kidney. (E) Isolated organ weights of mice ( $n=5$ mice/group). (F) HE staining of adipose tissues and oil-red staining of liver. Scale bar, $100 \mu \mathrm{m}$. (G) Serum leptin levels of mice ( $n=8$ mice/group). A full colour version of this figure is available at https:// doi.org/10.1530/JOE-19-0157. https://joe.bioscientifica.com https://doi.org/10.1530/JOE-19-0157 (c) 2019 Society for Endocrinology Published by Bioscientifica Ltd.
Printed in Great Britain 
of subcutaneous, epididymal fat and BAT of Dhtkd1-/mice were smaller than those of wt mice on either SCD or HFD (Fig. 2D). Except heart, almost all weighed tissues or organs were lighter in Dhtkd1 $1^{-/-}$mice compared with wt mice when they were fed with HFD (Fig. 2E). Wt mice fed with HFD and SCD for 6 months showed severe lipid droplet accumulation in the liver while relatively smaller adipocytes were found in Dhtkd1 ${ }^{-/}$mice compared to control mice (Fig. 2F). The serum leptin was significantly decreased in Dhtkd1-/- mice when they were fed with HFD, but it was comparable when fed with SCD (Fig. 2G). Plasma lipid-profile testing also demonstrated that the TC and triglyceride (TG) levels of $D h t k d 1^{-/-}$mice fed with SCD or HFD were obviously lower than those of wt littermates. In addition, the level of HDL-C was higher in Dhtkd1-/mice. Furthermore, some biochemical indexes, such as TP, ALB, GLOB, UA and CRE, were abnormal in SCD, while ALT, AST, LDH, BUN and CRE were abnormal in HFD (Supplementary Fig. 4B). Taken together, these results suggested that like 2-AAA-treated mice, Dhtkd1 ${ }^{-/-}$mice were also resistant to obesity. Besides, we aimed to detect whether the decreased weight in Dhtkd1-/- mice is due to reduced energy intake or increased energy expenditure. We found that Dhtkd1-/- mice consumed more food and less exercise than controls (Supplementary Fig. 5A). Increased energy expenditure rather than decreased food intake contributed to the weight loss in Dhtkd1-/- mice, which was further confirmed by increased $\mathrm{O}_{2}$ consumption, $\mathrm{CO}_{2}$ production, heat production and RER (Supplementary Fig. 5B), indicating that Dhtkd1-/- mice were always keeping in a high energy metabolic state.

\section{2-AAA enhanced thermogenesis in brown adipocytes}

The body temperatures of Dhtkd1-/- mice were almost able to be maintained in normal range up to $6 \mathrm{~h}$ in a cold environment $\left(4^{\circ} \mathrm{C}\right)$, while the body temperature of $\mathrm{wt}$ mice had fallen, even below $34^{\circ} \mathrm{C}$ (Fig. 3A). The increase in energy expenditure might reflect a high level of thermogenesis in Dhtkd1-/- mice. In fact, the expression

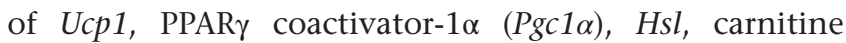
palmitoyltransferase $1 \mathrm{~B}(C p t 1 b)$, transcription factor A mitochondrial (Tfam), Adrb3, phytanoyl-CoA hydroxylase (Phyh), and Ppara, a number of brown fat-specific genes in BAT thermogenesis or mitochondria biogenesis were highly increased in the BAT of Dhtkd1 $1^{-/}$mice after exposed in $4^{\circ} \mathrm{C}$ for $4 \mathrm{~h}$ (Fig. 3B). As shown in Supplementary Fig. 6 , the expression of thermogenic genes were upregulated significantly in the BAT of 2-AAA-treated mice after $4 \mathrm{~h}$ exposure to $4^{\circ} \mathrm{C}$. But the differences were significantly narrowed at $24 \mathrm{~h}$. These indicated that the thermogenic effect of 2-AAA was of short duration. Western blotting confirmed that the protein of UCP1 and PGC1 $\alpha$ were

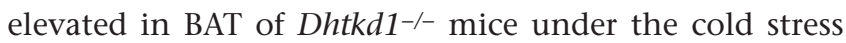
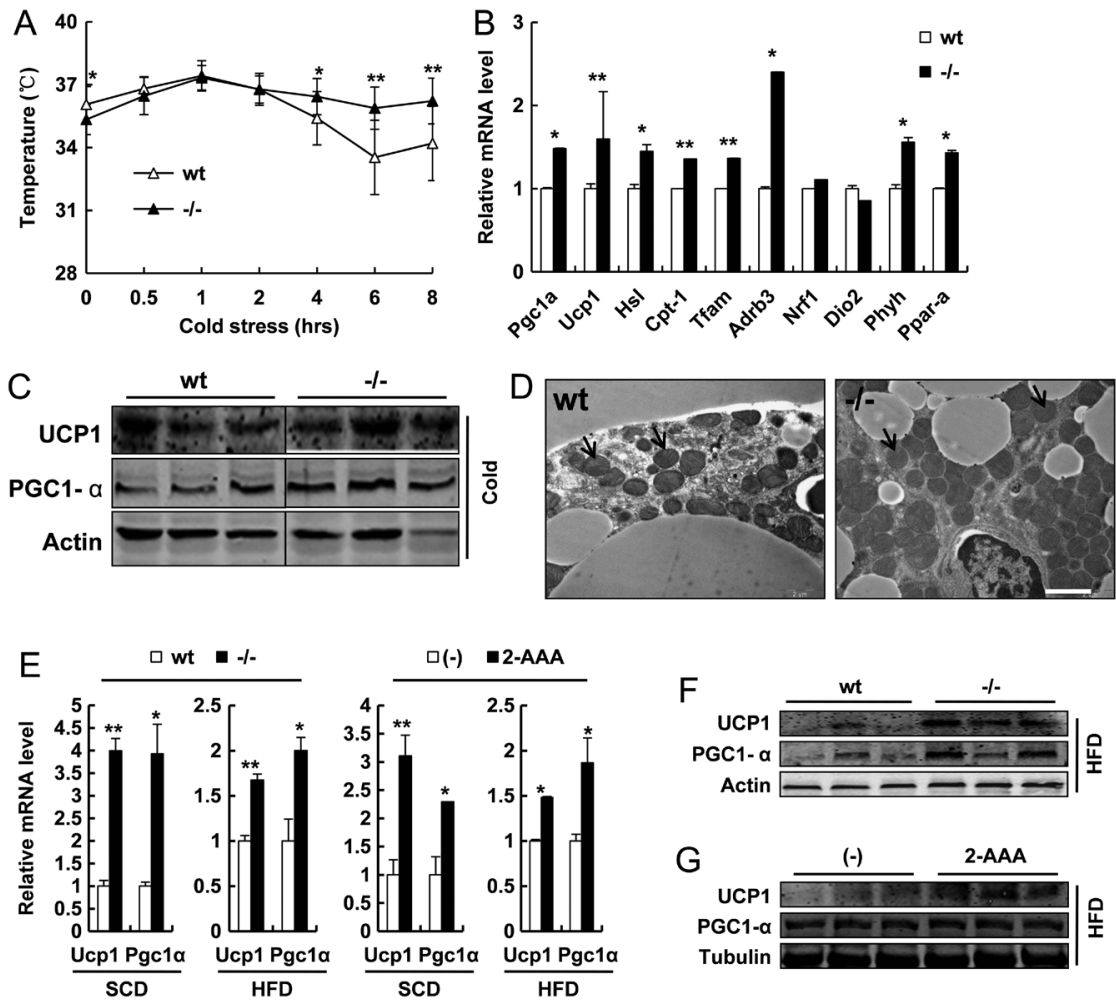

Figure 3

2-AAA administration promotes thermogenesis in BAT. (A) Body temperature changes of Dhtkd1-/and wt mice upon cold $\left(4^{\circ} \mathrm{C}\right)$ stress ( $n=10$ mice/ group). (B) RNA expression of thermogenic genes in BAT from mice $4 \mathrm{~h}$ after $4^{\circ} \mathrm{C}$ exposure. (C) Western blot analysis in BAT from mice $4 \mathrm{~h}$ after $4^{\circ} \mathrm{C}$ exposure. (D) TEM pictures of BAT from Dhtkd1--- and wt mice fed with HFD. Black arrows, mitochondria. Scale bar, $2 \mu \mathrm{m}$. (E) Ucp1 and Pgc1 $\alpha$ RNA expression in BAT. (F) Western blot analysis in BAT from Dhtkd1-/- and wt mice fed with HFD. (G) Western blot analysis in BAT from 2-AAAtreated mice fed with HFD. 
(Fig. 3C and Supplementary Fig. 7). Consistent with the higher oxygen consumption and enhanced energy expenditure described earlier, these results indicated that Dhtkd1/-/ mice displayed enhanced thermogenesis. Notably, though a significant alteration in the weight of interscapular BAT was detected in the Dhtkd1-/- mice with HFD, we observed a significant increase in the number of mitochondria in BAT of Dhtkd1 1/- mice by the electron microscope (Fig. 3D). This result indicated that absence of Dhtkd1 increased thermogenesis, partly because of an increase in mitochondria number. Like cold stimulation, we found the expression levels of UCP1 and PGC1 $\alpha$ were significantly increased in the BAT of Dhtkd1-deficient or 2-AAA-treated mice, whether they were fed with SCD or HFD (Fig. 3E, F and G). These observations suggested that enhanced energy dissipation in 2-AAA-treated or Dhtkd1-/mice were dependent on BAT-induced thermogenesis.

\section{2-AAA induced browning of epididymal WAT}

To determine whether increased adaptive thermogenesis was due to browning of WAT, we performed transcript and protein analysis and found that 2-AAA could induce a high expression of a number of brown fat-specific genes in WAT, including Ucp1, Pgc1a, Prdm16, Dio2 and Tfam (Fig. 4A and B). Among them, Ucp1 gene expression was extremely highly induced in the 2-AAA-treated mice, which was in accordance with the increased expression of Ucp1 gene in Dhtkd1-/- mice (Fig. 4A). Taken together, these data demonstrate that 2-AAA induces browning of WAT. Activation of $\beta 3 A R$ can induce a functional 'brownlike' adipocyte phenotype. In addition, $\beta 3$ AR stimulation triggers PKA-p38 (MAPK)-PGC1 $\alpha$ kinase cascade which induces UCP1-mediated thermogenesis. Consistently, we observed an increase in PKA and P38 phosphorylation in 2-AAA-treated and Dhtkd1-/- mice on HFD (Fig. 4C). Consistent with the in vivo data, the gene and protein expression of UCP1 and $\beta 3 A R$ was upregulated in differentiated 3T3-L1 adipocytes treated with 2-AAA (Fig. 4D, E and Supplementary Fig. 7).

\section{Lipolysis was enhanced in WAT of 2-AAA-treated and Dhtkd1-/- mice through activating $\beta 3 A R$ signaling}

We next explored whether the marked decrease in fat mass in the 2-AAA-treated and Dhtkd1-/- mice was due
A

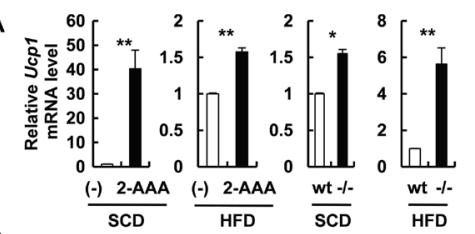

B

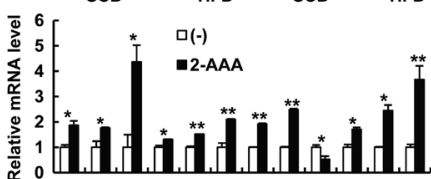

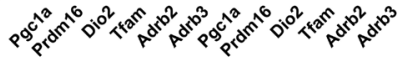
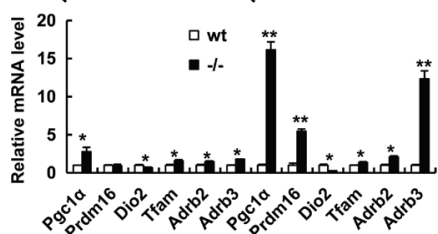

$\mathrm{D}$
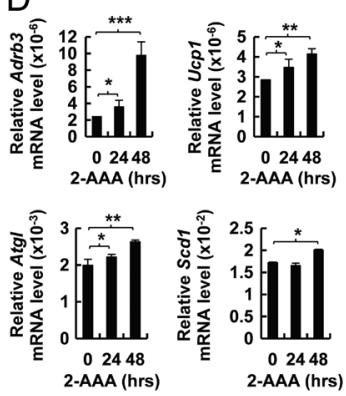

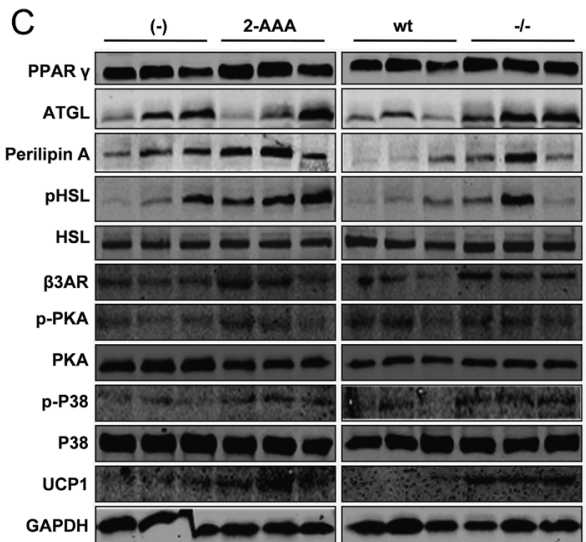

$\mathrm{F}$
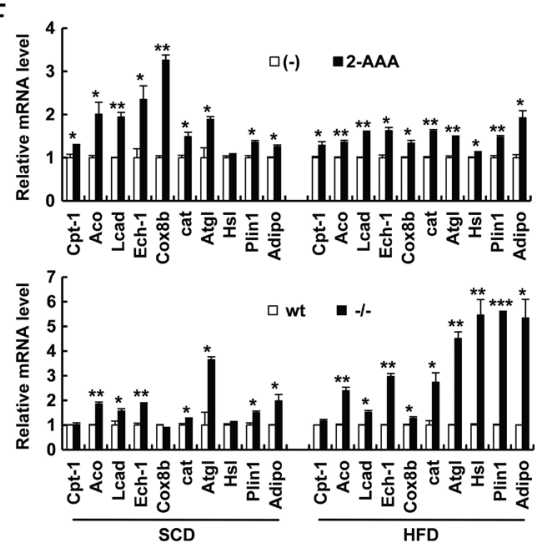

Figure 4

2-AAA intake enhances lipolysis and browning of WAT via activating $\beta 3 A R$ signaling. ( $A$ and $B$ ) mRNA expression of brown fat-specific genes in WAT. (C) Western blot analysis of lipolysis- and browningrelated proteins in WAT. (D) mRNA expression in 3T3L1 cells upon 2-AAA treatment. (E) Western blot analysis of proteins in 3T3L1 cells upon 2-AAA treatment for $48 \mathrm{~h}$. (F) mRNA expression of lipolysis-related genes in WAT. 
to alterations in lipid lipolysis, fat oxidation, lipogenesis, differentiation, mitochondrial biogenesis, thermogenesis or TG synthesis (Supplementary Fig. 8). A significant increase in key lipolytic enzymes at both mRNA and protein levels was detected in the epididymal fat from the 2-AAA-treated and Dhtkd1 $1^{--}$mice fed with HFD (Fig. 4C and F). HSL, a key enzyme controlling the adipocyte lipolytic activity, known to be highly regulated through adrenergic receptors, was found significantly increased in the epididymal fat of 2-AAA-treated and Dhtkd1-/- mice fed with HFD (Fig. 4F). Since the enzyme activity and translocation of HSL to lipid droplets need HSL phosphorylation, we conducted Western blot analysis and found a significant increase in the degree of HSL phosphorylation level in the epididymal fat from 2-AAA-treated and Dhtkd1-/- mice fed with HFD (Fig. 4C). Perilipin A is a protein covering the lipid droplets and serving as an essential interaction partner for HSL. The protein level of perilipin A showed a marked increase in the epididymal fat from 2-AAA-treated and Dhtkd1-/- mice fed with HFD (Fig. 4C). Another main lipase involved in the control of adipocyte lipolysis is desnutrin/ATGL, like HSL, which is regulated by adrenergic receptor activity. Also, 2-AAA-treated and Dhtkd1-/- mice had significantly higher levels of ATGL in their adipocytes (Fig. 4C and F). The two adrenergic receptors expressed in the dissected epididymal fat both increased in the 2-AAA-treated and Dhtkd1-/- mice. However, the $\beta 3 \mathrm{AR}$, which is more abundantly expressed in adipocytes, displayed a marked enhancement (Fig. 4B and C). Stimulation of $\beta 3 \mathrm{AR}$ signaling phosphorylates HSL and increases HSL-mediated lipolysis dependent on protein kinase A (PKA). As shown in Fig. 4C, we found that PKA phosphorylation was increased in the adipocytes in 2-AAA-treated and Dhtkd1-/- mice. Our results showed that $\beta 3 A R$-induced lipolysis via PKA-mediated HSL activation, leading to reduced fat mass in mice. This process produces a lot of fatty acids, but we did not found any pathological change in the liver (Supplementary Fig. 9). The biochemical indicators of liver function also showed no statistical difference (Supplementary Figs 1 and 4). These results suggest that increased lipolysis in adipocytes and reduced adiposity in the 2-AAA-treated or Dhtkd1 $1^{-/}$mice are mediated by specific regulation of $\beta 3 \mathrm{AR}$ to indirectly enhance HSL enzyme activity and induce UCP1-dependent thermogenesis related to $\beta 3 A R$ signaling.

\section{2-AAA was simulated to bind to $\beta 3 A R$}

Interestingly, computer simulation showed that 2-AAA binds to $\beta 3 A R$ (Supplementary Fig. 10). The binding sites were located at extracellular domain of $\beta 3 \mathrm{AR}$
(Supplementary Fig. 10A and B), and the optimal binding free energy was $-7.35 \mathrm{kcal} / \mathrm{mol}$. To evaluate whether the value was sufficient for their binding, we found a crystal structure of aspartate- $\beta$-semialdehide dehydrogenase from Streptococcus pneumoniae (spASADH) with 2',5'-adenosine diphosphate and D-2-AAA (PDB code, 3PWS). The optimal binding free energy of 2-AAA with spASADH was $-7.19 \mathrm{kcal} / \mathrm{mol}$, which was less than that of 2-AAA with $\beta 3 \mathrm{AR}$, suggesting that the binding of 2-AAA with $\beta 3 \mathrm{AR}$ was stabler than that with spASADH. Besides, the optimal binding free energy of 2-AAA with its enzyme, aminoadipate aminotransferase (AADAT), was $-7.71 \mathrm{kcal} / \mathrm{mol}$. The binding free energy obtained by molecular docking is linearly related to the molecular weight of small molecules (Zhao et al. 2018). Because the molecular weight of 2-AAA is relatively small, the binding free energy is relatively little. As a metabolic intermediate of lysine metabolism, 2-AAA has similar molecular weight with lysine. Thus, we found the free energy they bound with $\beta 3 A R$ are comparable. Furthermore, the binding of 2-AAA and $\beta 3 \mathrm{AR}$ mainly depended on the $\mathrm{N}$ atoms and the $\mathrm{O}$ atoms with double bonds (Supplementary Fig. 10C), and the sizes of hydrogen bonds were 1.84, 2.86, 2.59 and $2.76 \AA$, respectively (Supplementary Fig. 10D).

Recently, several clinical trials about $\beta 3 \mathrm{AR}$ agonist have failed due to problems of unspecific binding to $\beta 1 \mathrm{AR} / \beta 2 \mathrm{AR}$ resulting in tachycardia and tremors. We further examined cardiac parameters using ultrasound and found no significant difference between two groups (Supplementary Fig. 11).

\section{Effects of 2-AAA on glucose metabolism}

HFD-induced elevated blood glucose, impaired glycemic response, hyperinsulinemia and enhanced insulin resistance compared with mice fed with SCD. Daily administration of 2-AAA significantly reduced the overall glycemic levels of mice in HFD (Fig. 5A). Furthermore, plasma insulin concentration significantly descended to fasting insulin levels in 2-AAA-treated mice $2 \mathrm{~h}$ after feeding (Fig. 5B). GTT and ITT indicated that 2-AAAtreated mice showed improved glucose tolerance and insulin sensitivity as evidenced by lower blood glucose levels compared with controls on HFD (Fig. 5C and D). Thus, we supposed that elevated insulin sensitivity might be associated with the body weight of 2-AAA-treated or Dhtkd1-/- mice due to their lean phenotype. The PAS staining of liver indicated more glycogen accumulation in 2-AAA-treated mice compared with controls (Fig. 5E). Consistent with the effects of 2-AAA on glucose, Dhtkd1 

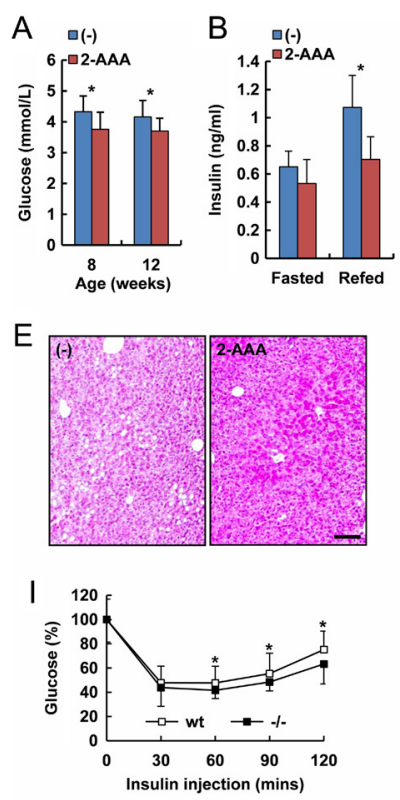
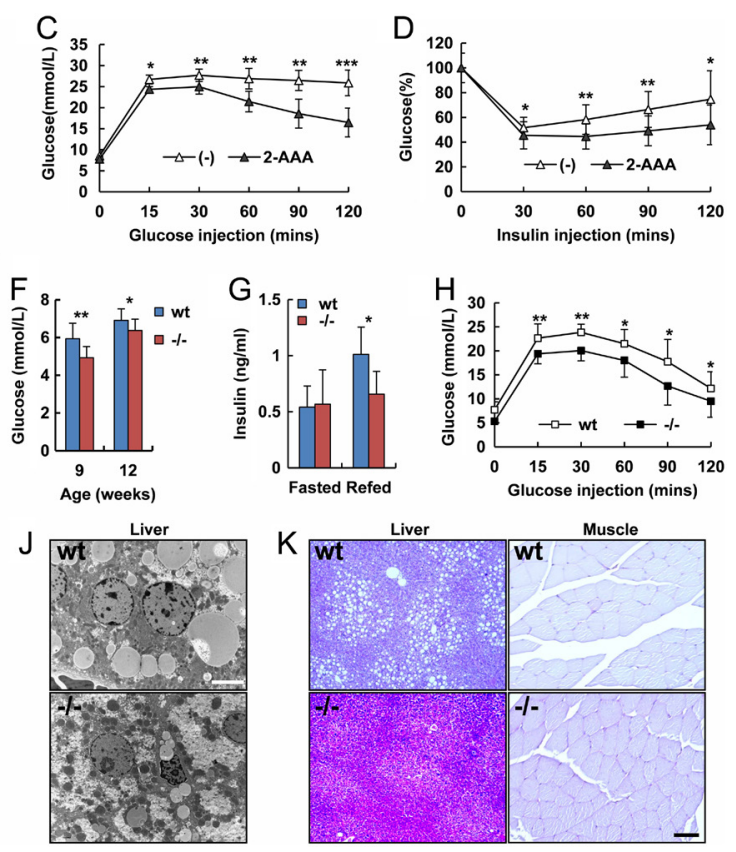

\section{Figure 5}

Both 2-AAA-treated and Dhtkd1-deficient mice show abnormal glucose metabolism induced by HFD. (A) Serum glucose levels of 2-AAA-treated mice fed with HFD ( $n=10$ mice/group). (B) Serum insulin levels of 2-AAA-treated mice fed with HFD ( $n=10$ mice/group). (C and D) GTT (C) and ITT (D) in 2-AAA-treated mice fed with HFD ( $n=8$ mice) group). (E) PAS staining of liver from 2-AAAtreated mice fed with HFD. Scale bar, $100 \mu \mathrm{m}$. (F) Serum glucose levels of $D h t k d 1^{-/-}$and wt mice fed with HFD ( $n=10$ mice/group). (G) Serum insulin levels of $D h t k d 1^{-/-}$and wt mice fed with HFD ( $n=10$ mice/group). (H and I) GTT (H) and ITT (I) in Dhtkd1 $1^{--}$and wt mice fed with HFD ( $n=8$ mice/ group). ()) TEM pictures of liver from Dhtkd1-/- and wt mice fed with HFD. Scale bar, $5 \mu \mathrm{m}$. (K) PAS staining of liver and muscle from Dhtkd1-/- and wt mice fed with HFD. Scale bar, $100 \mu \mathrm{m}$. A full colour version of this figure is available at https://doi. org/10.1530/JOE-19-0157. deficiency also caused lower serum glucose level and reduced postprandial hyperinsulinemia with HFD in mice (Fig. 5F and G). As expected, Dhtkd1 $1^{-/-}$mice also showed improved glucose tolerance and insulin sensitivity in GTT and ITT (Fig. 5H and I). The electron microscope analysis showed more glycogen combined with less and smaller lipid droplets in Dhtkd1-/- liver than those in wt mice (Fig. 5J) and the PAS staining showed more glycogen accumulation in the liver and skeletal muscle of Dhtkd1-/mice (Fig. 5K). Consistently, the glycogen synthesis-related genes expression was also upregulated in Dhtkd1-/- liver (Supplementary Fig. 12). These results suggested that improved HFD-induced glucose homeostasis existed in mice with high 2-AAA concentrations in vivo.

\section{2-AAA alleviated the diabetic symptoms of $d b / d b$ mice}

To assess the benefits of 2-AAA in therapies to ameliorate

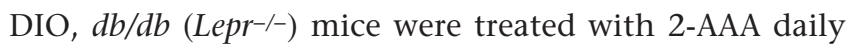
for 16 weeks. We found 2-AAA-treated $d b / d b$ mice were thinner than controls (Fig. 6A) combined with the decreased percentages of fat and lean mass in 2-AAAtreated $d b / d b$ mice (Fig. 6B). The weights of liver and WAT were obviously decreased in 2-AAA-treated mice than those of untreated mice (Fig. 6C). Consistent with improved glucose homeostasis in a genetically predisposed diabetes model with 2-AAA treatment, we observed that over-eat, over-drink and polyuria, as typical symptoms for diabetes, were obviously ameliorated in $d b / d b$ mice after 2-AAA intake (Fig. 6D and Supplementary Fig. 13A). In addition, $d b / d b$ mice developed obvious hyperglycemia, but those $d b / d b$ mice receiving 2-AAA showed a pronounced reduction in blood glucose after 1 week treatment (Fig. 6E). Elevated serum insulin levels after $30 \mathrm{~min}$ of refed were observed in 2-AAA-treated $d b / d b$ mice, suggesting an insulin sensitivity to food (Fig. 6F). Meanwhile, we found hepatic glycogen concentration in 2-AAA-treated $d b / d b$ mice was increased obviously (Fig. $6 \mathrm{G})$, suggesting that more glucose in peripheral blood was stored in liver in the form of glycogen. Intraperitoneal glucose and insulin challenge were performed to evaluate the effects of 2-AAA on significant promotion of glucose homeostasis and insulin resistance (Fig. $6 \mathrm{H}$ and I). Transcriptional analysis revealed that the upregulation of multiple key transcription factors involved in thermogenesis, mitochondrial biogenesis, peroxisomal fatty acid oxidation and lipolysis were correlated with ameliorating diabetic symptoms of $d b / d b$ mice under 2-AAA treatment (Supplementary Fig. 13B). Consistent with gene expression, the protein levels of adipose TG lipase (ATGL), the rate-limiting enzyme for lipolysis, perilipin A and pHSL were increased in 2-AAA-treated $d b / d b$ mice (Supplementary Fig. 13C). In summary, our findings revealed that the anti-obesity effect of 2-AAA was attributed to improve insulin resistance and alleviate metabolic disorders in diabetic mice. 

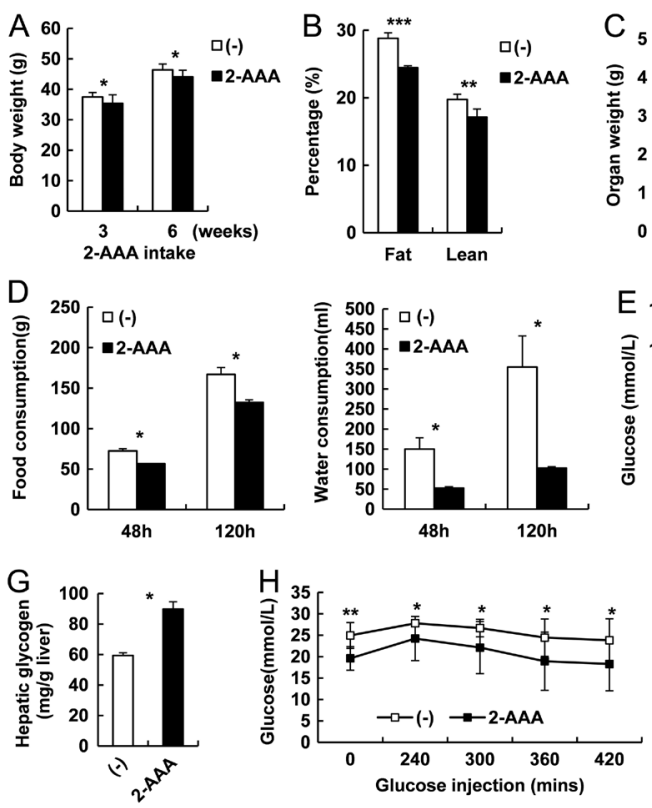
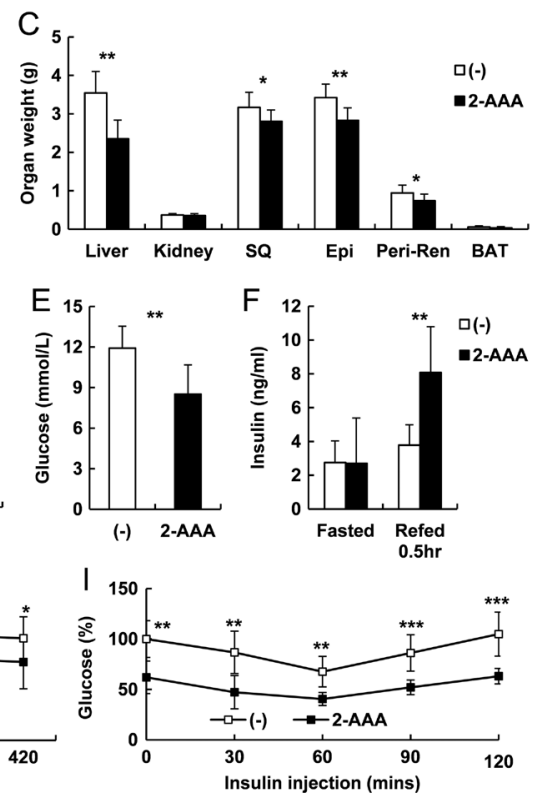

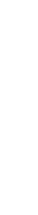

\begin{abstract}
Figure 6
2-AAA ameliorates diabetes mellitus symptoms in $d b / d b$ mice. (A) Body weights of 2-AAA-treated $d b / d b$ mice ( $n=9$ mice/group). (B) MRI analysis of the contents of fat mass and lean mass in 2-AAA-treated $d b / d b$ mice ( $n=5$ mice/group). (C) Organ weights of 2-AAA-treated and -untreated $d b / d b$ mice ( $n=5$ mice/group). (D) Food and water consumption of 2-AAA-treated ( 3 weeks) and untreated $d b / d b$ mice ( $n=5$ mice/group). (E) Serum glucose levels of 2-AAA-treated $d b / d b$ mice ( $n=9$ mice/group). (F) Serum insulin levels of 2-AAA-treated $d b / d b$ mice ( $n=9$ mice/group). (G) Hepatic glycogen of 2-AAA-treated $d b / d b$ mice ( $n=3$ mice/group). ( $\mathrm{H}$ and $\mathrm{I}$ ) GTT $(\mathrm{H})$ and ITT $(\mathrm{I})$ in 2-AAA-treated $d b / d b$ mice ( $n=9$ mice/group).
\end{abstract}

\section{Discussion}

The accumulation of 2-AAA in the body is the major cause of 2-aminoadipic and 2-oxoadipic aciduria and Charcot-Marie-Tooth disease 2Q (Danhauser et al. 2012, $\mathrm{Xu}$ et al. 2018). But one thing has two sides. 2-AAA also brings us the gospel. Previous studies showed that after exogenous administration of 2-AAA, high levels of 2-AAA were detected in islets and adipose tissues (Wang et al. 2013), indicating that its major action sites were probably in islets and adipocytes. Our previous results also showed that mice with DHTKD1 deficiency caused 2-AAA accumulation to increase insulin production and secretion (Xu et al. 2018). In addition, diabetic patients were found to have a significant decrease in 2-AAA levels (Wu et al. 2014), indicating the effect of 2-AAA on the development of diabetes. As we observed in this study, 2-AAA is responsible for the improvement of glycolipid metabolism and insulin sensitivity, thus making mice resistant to DIO independent of diet and exercise.

In this study, 2-AAA-fed mice showed weight loss, decreasedadipocytesand reducedbodyfat, which weremore pronounced in the HFD. Increased oxygen consumption, carbon dioxide production and heat production no matter on normal diet or HFD, suggesting 2-AAA-treated mice are in a state of hypermetabolism. Thermogenesis in BAT contributed to increased energy metabolism in the 2-AAA-treated mice. BAT has long been considered to be the primary tissue responsible for thermogenesis, in which process, PGC1 $\alpha$ and UCP1 play crucial roles (Puigserver \& Spiegelman 2003, Ricquier 2005). PGC1 $\alpha$ can regulate the expression of mitochondrial protein UCP1 and improve the mitochondrial oxidation capacity. The expression of thermogenesis-related genes, including $U c p 1, P g c 1 \alpha$ and Ppar $\alpha$, was increased significantly in the BAT of 2-AAAtreated mice. The expression level of UCP1 also increased significantly in the WAT of 2-AAA-treated mice, suggesting that 2-AAA could promote the transformation from WAT to BAT, and in addition, the expression of lipogenesis and

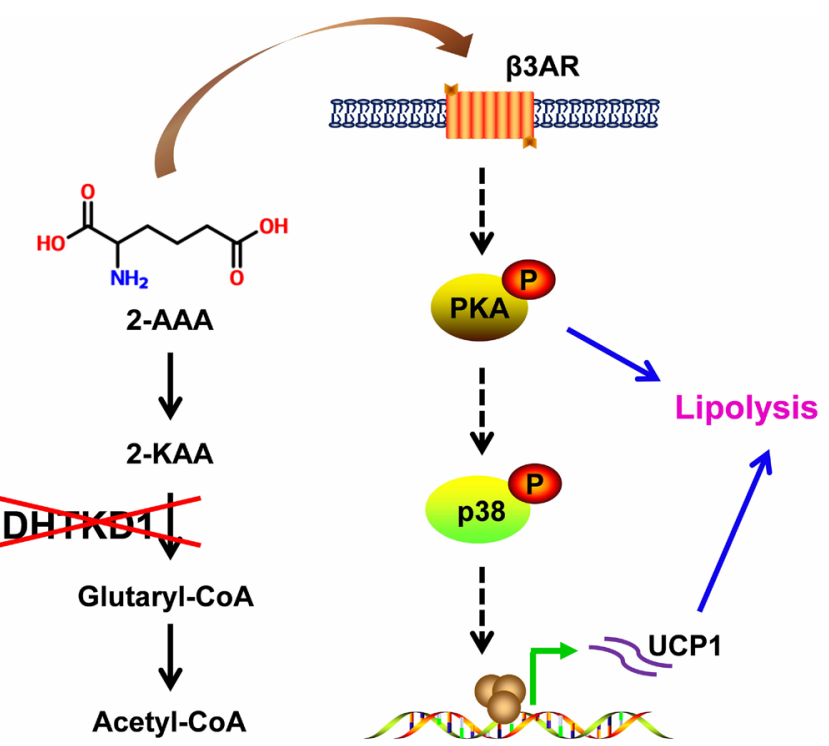

Figure 7

Schematic representation of the potential mechanisms of DHTKD1 and 2-AAA in lipolysis. Loss of function of DHTKD1 causes obvious increase of 2-AAA level. Then accumulated 2-AAA overactivates $\beta 3$ AR signaling, leading to enhanced lipolysis and thermogenesis. A full colour version of this figure is available at https://doi.org/10.1530/JOE-19-0157. 
lipolysis genes was upregulated in WAT. We found that the expression of HSL and ATGL, which controlled lipolysis, increased significantly in WAT of 2-AAA-fed mice. ATGL mainly promotes triglyceride hydrolysis (Villena et al. 2004, Zimmermann et al. 2004) and phosphorylated HSL mainly promotes the hydrolysis process of diacylglycerol (Vaughan et al. 1964, Zechner et al. 2009). These results suggest that, on one hand, the lipogenesis increases with the action of insulin; on the other hand, lipolysis also increases. The activation of ATGL and HSL will help to reduce triglyceride storage in various tissues and organs and resist DIO and diacylglycerol accumulation (Osuga et al. 2000, Harada et al. 2003, Haemmerle et al. 2006). Since the activation of $\beta A R$ is considered to be the major marker of lipolysis (Zechner et al. 2009), the upregulation of transcripts, Adrb2 and Adrb3, in the WAT of 2-AAAfed mice demonstrated that 2-AAA promoted lipolysis. Computer simulation showed that 2-AAA binds to $\beta 3 \mathrm{AR}$ at extracellular domain of $\beta 3 \mathrm{AR}$. Pharmacological $\beta 3 \mathrm{AR}$ activation leads to increased adipose 'browning' and insulin release. Epinephrine or the $\beta 3 \mathrm{AR}$ agonist such as CL 316,243 (CL) are aimed to improve metabolic function to treat obesity. Natural metabolite 2-AAA-mediated DIO resistance is via stimulated adrenergic signaling pathways mainly involving $\beta 3 \mathrm{AR}$. Moreover, presumed as a $\beta 3 \mathrm{AR}$ agonist, enhanced 2-AAA contents led to a browning response in inguinal (iWAT), along with reduced WAT and BAT mass regardless of high fat intake.

2-AAA enhances energy metabolism and reduces the accumulation of fat, one of the greatest benefits of which is that it will improve glucose metabolism and increase insulin sensitivity in mice. Actually, we observed that 2-AAA-fed mice showed increased insulin sensitivity, decreased blood glucose and improved glucose tolerance, which was more obvious in HFD-fed mice. The relationship between lipid metabolism and insulin sensitivity mainly reflects in two aspects. First, 2-AAA reduces the size of adipocyte, and smaller adipocytes are more sensitive to insulin stimulation (Foley et al. 1980, Bluher et al. 2002). Second, besides WAT, increased triglyceride will also accumulate in other tissues or organs, such as liver and muscle, which will weaken the effect of insulin on fat cells and reduce insulin sensitivity (Hulver \& Dohm 2004). Given an HFD, the mice showed an increased amount of fat cells, excessive triglycerides stored in the liver and muscle, and weakened effect of insulin on fat cells. But when given 2-AAA simultaneously, the mice showed enhanced hydrolysis of fat in the liver and muscles, and enhanced insulin sensitivity, so they resisted to DIO. Our research demonstrates that the metabolite 2-AAA could stimulate insulin synthesis and secretion and improve insulin sensitivity. When 2-AAA is used as a treatment tool, we found that 2-AAA could decrease blood glucose of diabetic $d b / d b$ mice and significantly improve their symptoms of diabetes mellitus. Although its effects on reducing weight in $d b / d b$ mice were not as obvious as those in wt mice, it still reduced fat accumulation, enhanced lipolysis and increased insulin sensitivity in $d b / d b$ mice.

DHTKD1 participates in lysine metabolism and catalyzes the conversion of 2-oxoglutarate to succinylCoA and regulates 2-AAA levels in both mice and humans (Danhauser et al. 2012, Wu et al. 2014, Xu et al. 2018). DHTKD1/2-AAA axis was highlighted by that reduced in DHTKD1 levels was associated with higher urinary 2-AAA levels in Dhtkd1-/- mice (Xu et al. 2018). Our studies reveal that Dhtkd1-/- mice exhibited weight loss, active energy metabolism, and increased lipid hydrolysis and free fatty acid $\beta$-oxidation, resulting in decreased WAT volume and triglyceride content. At the same time, the increase of UCP1 expression in Dhtkd1-/- BAT may increase thermogenesis, which enhances the energy metabolic status, eventually leading to increased insulin sensitivity and resistant to age or HFD-induced obesity. We have known that Dhtkd1 deficiency leads to metabolic substrate 2-AAA accumulation. Therefore, we hypothesized that abnormal metabolic status found in $D h t k d 1^{-/-}$mice was actually closely related to 2-AAA. Then we artificially fed mice with 2-AAA. Consequently, we found similar phenotypes in 2-AAA-fed mice to those found in Dhtkd1 $1^{-/-}$mice. Our study identifies that DHTKD1 influences lipid metabolism through regulation of 2-AAA levels in both humans and mice. Obesity can cause a lot of health hazards. Among them, cardiovascular disease and diabetes are the major complications with a high concentration of plasma lipid and glucose levels. Nowadays, serum lipid levels can be decreased by statin drugs and diabetes are treated with various hypoglycemic drugs or insulin. Despite the availability of drug and surgical therapeutics, many individuals are intolerant to drugs. Thus, gene therapy brings new directions for treatment, and elevated 2-AAA levels via the inhibition of DHTKD1 may provide a new direction for treating obesity or diabetes.

Overall, the results of our study demonstrated to harness metabolic 2-AAA as a natural regulator in the clinical management of glycolipid metabolism (Fig. 7). It will be a star project that how to reduce the toxicity of 2-AAA to peripheral nerve to the minimum, while using it to treat obesity or diabetes. Anyhow, we hope to extract the essence and discard the dross, making the culprit that causes the human amino acid metabolic and peripheral nervous system diseases benefit the world. 


\section{Supplementary data}

This is linked to the online version of the paper at https://doi.org/10.1530/ JOE-19-0157.

\section{Declaration of interest}

The authors declare that there is no conflict of interest that could be perceived as prejudicing the impartiality of the research reported.

\section{Funding}

This work was supported by the National Natural Science Foundation of China (81201365 to W Y X, 81430028 to Z G W and 81502048 to H Z), the Ministry of Science and Technology of China (2011BAl15B02 to Z G W), the Science and Technology Commission of Shanghai Municipality (13DZ2280600, 13DZ2293700 and 15DZ2290800 to Z G W), and the E-Institutes of Shanghai Municipal Education Commission (E03003 to $Z$ G W).

\section{Author contribution statement}

$W Y X, H Z$ and $Z G W$ designed experiments and discussed data. $W Y X, Y$ S, H Z, J G, C Z, L T and Y H W performed experiments, and analyzed and interpreted data. $L T, S Y L, C L S$ and $H X Z$ provided reagents and materials. $W Y X, H Z, P M$ and $Z L$ wrote the manuscript. J F participated in discussing data. Z G W supervised the work.

\section{Acknowledgments}

The authors are very grateful to Xiaodie Tu for her help in pathological sections of adipose tissues.

\section{References}

Alejandro EU, Gregg B, Blandino-Rosano M, Cras-Meneur C \& BernalMizrachi E 2015 Natural history of beta-cell adaptation and failure in type 2 diabetes. Molecular Aspects of Medicine 42 19-41. (https://doi. org/10.1016/j.mam.2014.12.002)

Argyropoulos G \& Harper ME 2002 Uncoupling proteins and thermoregulation. Journal of Applied Physiology 92 2187-2198. (https://doi.org/10.1152/japplphysiol.00994.2001)

Ashcroft FM \& Rorsman P 2012 Diabetes mellitus and the beta cell: the last ten years. Cell 148 1160-1171. (https://doi.org/10.1016/j. cell.2012.02.010)

Bluher M, Michael MD, Peroni OD, Ueki K, Carter N, Kahn BB \& Kahn CR 2002 Adipose tissue selective insulin receptor knockout protects against obesity and obesity-related glucose intolerance. Developmental Cell 3 25-38. (https://doi.org/10.1016/S15345807(02)00199-5)

Calle EE, Rodriguez C, Walker-Thurmond K \& Thun MJ 2003 Overweight, obesity, and mortality from cancer in a prospectively studied cohort of U.S. adults. New England Journal of Medicine 348 1625-1638. (https://doi.org/10.1056/NEJMoa021423)

Colberg SR \& Sigal RJ 2011 Prescribing exercise for individuals with type 2 diabetes: recommendations and precautions. Physician and Sportsmedicine 39 13-26. (https://doi.org/10.3810/ psm.2011.05.1909)
Danhauser K, Sauer SW, Haack TB, Wieland T, Staufner C, Graf E, Zschocke J, Strom TM, Traub T, Okun JG, et al. 2012 DHTKD1 mutations cause 2-aminoadipic and 2-oxoadipic aciduria. American Journal of Human Genetics 91 1082-1087. (https://doi.org/10.1016/j. ajhg.2012.10.006)

De Matteis R, Arch JR, Petroni ML, Ferrari D, Cinti S \& Stock MJ 2002 Immunohistochemical identification of the beta(3)-adrenoceptor in intact human adipocytes and ventricular myocardium: effect of obesity and treatment with ephedrine and caffeine. International Journal of Obesity and Related Metabolic Disorders 26 1442-1450. (https://doi.org/10.1038/sj.ijo.0802148)

Fildes A, Charlton J, Rudisill C, Littlejohns P, Prevost AT \& Gulliford MC 2015 Probability of an obese person attaining normal body weight: cohort study using electronic health records. American Journal of Public Health 105 e54-e59. (https://doi.org/10.2105/AJPH.2015.302773)

Flegal KM, Kit BK, Orpana H \& Graubard BI 2013 Association of all-cause mortality with overweight and obesity using standard body mass index categories: a systematic review and meta-analysis. JAMA 309 71-82. (https://doi.org/10.1001/jama.2012.113905)

Foley JE, Laursen AL, Sonne O \& Gliemann J 1980 Insulin binding and hexose transport in rat adipocytes. Relation to cell size. Diabetologia 19 234-241. (https://doi.org/10.1007/bf00275275)

Gonzalez-Muniesa P, Martinez-Gonzalez MA, Hu FB, Despres JP, Matsuzawa Y, Loos RJF, Moreno LA, Bray GA \& Martinez JA 2017 Obesity. Nature Reviews: Disease Primers 3 17034. (https://doi. org/10.1038/nrdp.2017.34)

Guerra C, Koza RA, Yamashita H, Walsh K \& Kozak LP 1998 Emergence of brown adipocytes in white fat in mice is under genetic control. Effects on body weight and adiposity. Journal of Clinical Investigation $\mathbf{1 0 2}$ 412-420. (https://doi.org/10.1172/JCI3155)

Haemmerle G, Lass A, Zimmermann R, Gorkiewicz G, Meyer C, Rozman J, Heldmaier G, Maier R, Theussl C, Eder S, et al. 2006 Defective lipolysis and altered energy metabolism in mice lacking adipose triglyceride lipase. Science $\mathbf{3 1 2}$ 734-737. (https://doi. org/10.1126/science.1123965)

Hagen J, te Brinke H, Wanders RJ, Knegt AC, Oussoren E, Hoogeboom AJ, Ruijter GJ, Becker D, Schwab KO, Franke I, et al. 2015 Genetic basis of alpha-aminoadipic and alpha-ketoadipic aciduria. Journal of Inherited Metabolic Disease 38 873-879. (https://doi.org/10.1007/s10545-0159841-9)

Harada K, Shen WJ, Patel S, Natu V, Wang J, Osuga J, Ishibashi S \& Kraemer FB 2003 Resistance to high-fat diet-induced obesity and altered expression of adipose-specific genes in HSL-deficient mice. American Journal of Physiology: Endocrinology and Metabolism 285 E1182-E1195. (https://doi.org/10.1152/ajpendo.00259.2003)

Hulver MW \& Dohm GL 2004 The molecular mechanism linking muscle fat accumulation to insulin resistance. Proceedings of the Nutrition Society 63 375-380. (https://doi.org/10.1079/PNS2004351)

Jensen MD, Ryan DH, Apovian CM, Ard JD, Comuzzie AG, Donato KA, Hu FB, Hubbard VS, Jakicic JM, Kushner RF, et al. 20142013 AHA/ ACC/TOS guideline for the management of overweight and obesity in adults: a report of the American College of Cardiology/American Heart Association Task Force on Practice Guidelines and the Obesity Society. Journal of the American College of Cardiology 63 2985-3023. (https://doi.org/10.1016/j.jacc.2013.11.004)

Kajimura S, Seale P \& Spiegelman BM 2010 Transcriptional control of brown fat development. Cell Metabolism 11 257-262. (https://doi. org/10.1016/j.cmet.2010.03.005)

Klaus S 1997 Functional differentiation of white and brown adipocytes. BioEssays 19 215-223. (https://doi.org/10.1002/bies.950190307)

Lafontan M \& Berlan M 2003 Do regional differences in adipocyte biology provide new pathophysiological insights? Trends in Pharmacological Sciences 24 276-283. (https://doi.org/10.1016/S01656147(03)00132-9)

Lee YH, Petkova AP, Mottillo EP \& Granneman JG 2012 In vivo identification of bipotential adipocyte progenitors recruited by beta3- 
adrenoceptor activation and high-fat feeding. Cell Metabolism $\mathbf{1 5}$ 480-491. (https://doi.org/10.1016/j.cmet.2012.03.009)

Lee YH, Mottillo EP \& Granneman JG 2014 Adipose tissue plasticity from WAT to BAT and in between. Biochimica and Biophysica Acta 1842 358-369. (https://doi.org/10.1016/j.bbadis.2013.05.011)

Lonnqvist F, Krief S, Strosberg AD, Nyberg S, Emorine LJ \& Arner P 1993 Evidence for a functional beta 3-adrenoceptor in man. British Journal of Pharmacology 110 929-936. (https://doi. org/10.1111/j.1476-5381.1993.tb13902.x)

Lonnqvist F, Thome A, Nilsell K, Hoffstedt J \& Arner P 1995 A pathogenic role of visceral fat beta 3-adrenoceptors in obesity. Journal of Clinical Investigation 95 1109-1116. (https://doi.org/10.1172/JCI117758)

Osuga J, Ishibashi S, Oka T, Yagyu H, Tozawa R, Fujimoto A, Shionoiri F, Yahagi N, Kraemer FB, Tsutsumi O, et al. 2000 Targeted disruption of hormone-sensitive lipase results in male sterility and adipocyte hypertrophy, but not in obesity. PNAS 97 787-792. (https://doi. org/10.1073/pnas.97.2.787)

Puigserver P \& Spiegelman BM 2003 Peroxisome proliferator-activated receptor-gamma coactivator 1 alpha (PGC-1 alpha): transcriptional coactivator and metabolic regulator. Endocrine Reviews 24 78-90. (https://doi.org/10.1210/er.2002-0012)

Ricquier D 2005 Respiration uncoupling and metabolism in the control of energy expenditure. Proceedings of the Nutrition Society 64 47-52. (https://doi.org/10.1079/PNS2004408)

Ricquier D, Bouillaud F, Toumelin P, Mory G, Bazin R, Arch J \& Penicaud L 1986 Expression of uncoupling protein mRNA in thermogenic or weakly thermogenic brown adipose tissue. Evidence for a rapid beta-adrenoreceptor-mediated and transcriptionally regulated step during activation of thermogenesis. Journal of Biological Chemistry 261 13905-13910.

Seale P, Conroe HM, Estall J, Kajimura S, Frontini A, Ishibashi J, Cohen P, Cinti S \& Spiegelman BM 2011 Prdm16 determines the thermogenic program of subcutaneous white adipose tissue in mice. Journal of Clinical Investigation 121 96-105. (https://doi.org/10.1172/JCI44271)

Shabalina IG, Petrovic N, de Jong JM, Kalinovich AV, Cannon B \& Nedergaard J 2013 UCP1 in Brite/beige adipose tissue mitochondria is functionally thermogenic. Cell Reports 5 1196-1203. (https://doi. org/10.1016/j.celrep.2013.10.044)

Spandidos A, Wang X, Wang H \& Seed B 2010 PrimerBank: a resource of human and mouse PCR primer pairs for gene expression detection and quantification. Nucleic Acids Research 38 D792-D799. (https://doi. org/10.1093/nar/gkp1005)

Vaughan M, Berger JE \& Steinberg D 1964 Hormone-sensitive lipase and monoglyceride lipase activities in adipose tissue. Journal of Biological Chemistry 239 401-409.

Villena JA, Roy S, Sarkadi-Nagy E, Kim KH \& Sul HS 2004 Desnutrin, an adipocyte gene encoding a novel patatin domain-containing protein, is induced by fasting and glucocorticoids: ectopic expression of desnutrin increases triglyceride hydrolysis. Journal of
Biological Chemistry 279 47066-47075. (https://doi.org/10.1074/jbc. M403855200)

Wang TJ, Ngo D, Psychogios N, Dejam A, Larson MG, Vasan RS, Ghorbani A, O'Sullivan J, Cheng S, Rhee EP, et al. 2013 2-Aminoadipic acid is a biomarker for diabetes risk. Journal of Clinical Investigation 123 4309-4317. (https://doi.org/10.1172/JCI64801)

Wu J, Bostrom P, Sparks LM, Ye L, Choi JH, Giang AH, Khandekar M, Virtanen KA, Nuutila P, Schaart G, et al. 2012 Beige adipocytes are a distinct type of thermogenic fat cell in mouse and human. Cell $\mathbf{1 5 0}$ 366-376. (https://doi.org/10.1016/j.cell.2012.05.016)

Wu Y, Williams EG, Dubuis S, Mottis A, Jovaisaite V, Houten SM, Argmann CA, Faridi P, Wolski W, Kutalik Z, et al. 2014 Multilayered genetic and omics dissection of mitochondrial activity in a mouse reference population. Cell 158 1415-1430. (https://doi.org/10.1016/j. cell.2014.07.039)

Xu WY, Gu MM, Sun LH, Guo WT, Zhu HB, Ma JF, Yuan WT, Kuang Y, Ji BJ, Wu XL, et al. 2012 A nonsense mutation in DHTKD1 causes Charcot-Marie-Tooth disease type 2 in a large Chinese pedigree. American Journal of Human Genetics 91 1088-1094. (https://doi. org/10.1016/j.ajhg.2012.09.018)

Xu W, Zhu H, Gu M, Luo Q, Ding J, Yao Y, Chen F \& Wang Z 2013 DHTKD1 is essential for mitochondrial biogenesis and function maintenance. FEBS Letters 587 3587-3592. (https://doi.org/10.1016/j. febslet.2013.08.047)

Xu WY, Zhu H, Shen Y, Wan YH, Tu XD, Wu WT, Tang L, Zhang HX, Lu SY, Jin XL, et al. 2018 DHTKD1 deficiency causes Charcot-MarieTooth disease in mice. Molecular and Cellular Biology 38 e00085-18. (https://doi.org/10.1128/MCB.00085-18)

Xue B, Rim JS, Hogan JC, Coulter AA, Koza RA \& Kozak LP 2007 Genetic variability affects the development of brown adipocytes in white fat but not in interscapular brown fat. Journal of Lipid Research 48 41-51. (https://doi.org/10.1194/jlr.M600287-JLR200)

Yehuda-Shnaidman E, Buehrer B, Pi J, Kumar N \& Collins S 2010 Acute stimulation of white adipocyte respiration by PKA-induced lipolysis. Diabetes 59 2474-2483. (https://doi.org/10.2337/db10-0245)

Zechner R, Kienesberger PC, Haemmerle G, Zimmermann R \& Lass A 2009 Adipose triglyceride lipase and the lipolytic catabolism of cellular fat stores. Journal of Lipid Research 50 3-21. (https://doi. org/10.1194/jlr.R800031-JLR200)

Zhao XH, Wang XL \& Li Y 2018 Relationship between the binding free energy and PCbs' migration, persistence, toxicity and bioaccumulation using a combination of the molecular docking method and 3D-QSAR. Chemistry Central Journal 12 20. (https://doi. org/10.1186/s13065-018-0389-2)

Zimmermann R, Strauss JG, Haemmerle G, Schoiswohl G, BirnerGruenberger R, Riederer M, Lass A, Neuberger G, Eisenhaber F, Hermetter A, et al. 2004 Fat mobilization in adipose tissue is promoted by adipose triglyceride lipase. Science 306 1383-1386. (https://doi.org/10.1126/science.1100747)

Received in final form 28 July 2019

Accepted 20 August 2019

Accepted Preprint published online 21 August 2019 https://joe.bioscientifica.com https://doi.org/10.1530/JOE-19-0157 (c) 2019 Society for Endocrinology Published by Bioscientifica Ltd. 